\title{
PEDOGEOMORFOLOGIA E MICROPEDOLOGIA DE UMA SEQUÊNCIA LATOSSOLO - AREIA QUARTZOSA HIDROMÓRFICA SOBRE ROCHAS CRISTALINAS DO ESTADO DO AMAZONAS
}

\author{
Hélcio Andrade(*), Carlos Ernesto G. R. Schaefer(**), José Luiz Ioriatti Demattê(***) \& \\ Felipe Vaz Andrade (****)
}

\begin{abstract}
The pedogenesis of a latosol - plinthic podzolic latosol - hydromorphic quartzous sand sequence was studied, with respect to its chemical, physical and mineralogical properties. These soils are developed from crystalline substratum of the Guiana Complex, in the Occidental Amazon. The studied area is located in the Waimiri-Atroari Indigenous reserve, at the Km 160 of the BR 174, which links Manaus to Caracaraí. The toposequence represents a hill formed by clayey soils in the top of the landscape, ending in a broad valley flat with sandy soils in the bottom, under strong hydromorphism. The temperature and moisture regime of the soils are isohypertermic to hyperthermic, and udic to aquic, from the higher parts to the valley bottom, respectively. Six trenches were open and described in detail; in addition, core samples were examinated in six extra sites.

Four soil profiles representatives of the segments ( latosolic, transition and hidromorphic) were selected for the study of physical, chemical, mineralogical and micromorphological characteristics of their components. The higher part of the sequence is dominated by red-yellow latosol, the transition segment by plinthic podzolic intergrade to red-yellow latosol, and the lower parts by hidromorphic quartzous sand. The parent material of the soil of all the sequence is heterogeneous, but basically derived from wheathered granitic rock, with some localized influence of alteration products of mafic rocks. All soils have a high aluminum saturation. In the higher parts of the sequence the textural gradient is lower and the clay fraction is dominated by kaolinite and crystalline iron oxides. Downslope the textural gradient increases and the iron forms are less crystalline. At the valley bottom rests a deep sandy mantle, where iron oxides are absent, remaining traces of kaolinite. Mica/illite were found in the deeper parts of the soils and hydroxide-interlayered vermiculite in the upper parts. The sequence of evolution is processed mainly by pedological transformation involving seasonal acid and hydromorphic conditions, where ferrolysis occurs. This process leads to a lateral degradation of the latosolic material of the top of the landscape, with clay destruction and concentration of sandy materials dominated by quartz. Micropedological features related to the ferrolysis process are presented and discussed.
\end{abstract}

\section{INTRODUÇÃO}

O conhecimento dos solos da Amazônia, desde os estudos pioneiros, iniciados por naturalistas dos séculos XVIII e XIX, como Alexandre R. Ferreira, Louis Agassiz, Charles Hartt, e culminando com a expedição pedológica de Marbuti, em 1925/26, encerram um capítulo onde as primeiras observações esparsas e qualitativas dão lugar à estudos e levantamentos sistemáticos que permitem uma visão bem mais ampla e integrada dos solos, em termos de suas características químicas, físicas e mineralógicas, e de suas relações com a evolução geomorfológica regional (Day, 1958, 1959; Klinge, 1966; Sombroek, 1966; Falest, 1967, 1970, 1972; Vieira, 1971; Rodrigues et al., 1971; Kitagawa \& Möller, 1977; RADAMBRASIL, 1975, 1978; EMBRAPA, 1979a; UFV, 1979; Cochrante \& Sanches, 1982; LUCAS et al., 1984; Andrade, 1990; Schaefer, 1994; Rodrigues, 1995; Schaefer \& Dalrymple, 1996; Schaefer, 1997). O amplo acêrvo de dados pedológicos, hoje disponível, permite o reconhecimento da enorme diversidade pedológica dos solos da Amazônia, até então desconhecida.
Na porção norte da bacia Amazônica, ao longo dos rios formadores das Bacias do Rio Negro e Baixo Rio Branco, as pedopaisagens mais típicas são formadas por colinas convexas suaves, com solos argilosos de topo (Latossolos) que gradam vertente abaixo para vales amplos de fundo chato, onde predominam solos arenosos, hidromórficos (Areias Quartzosas Hidromórficas, Podzóis Hidromórficos). Os primeiros estudos interpretaram uma sequência associada com sedimentação grosseira, arenosa e mal-selecionada, onde a pedogênese posterior originou solos arenosos, hidromórficos (Klinge, 1965; EMBRAPA, 1979a; RADAMBRASIL, 1978). Estudos mais recentes, contudo, propuseram uma origem autóctone para esta gradação sobre sedimentos do tipo Barreiras, que seria assim, mais um produto da pedogênese do que sedimentação (Chauvel, 1981, 1982). Nesse modelo, a intensa hidrólise em ambiente ácido, com destruição do plasma argiloso seria responsável pela concentração seletiva dos grãos arenosos do esqueleto, dominantemente quartzoso. Assim, não haveria necessidade de postular-se mecanismos de sedimentação arenosa nos vales para explicar a 
presença desses solos arenosos profundos.

O presente estudo objetivou a caracterização detalhada de uma sequência argilosa-arenosa semelhante, originada de produtos de decomposição de rochas cristalinas ácidas, contrastando assim com os estudos anteriores, todos em solos desenvolvidos de sedimentos Terciários do Grupo Barreiras.

\section{MATERIAL E MÉTODOS}

A área selecionada corresponde à uma colina convexo-convexa sobre material granítico do Complexo Cristalino Guianense, coberta por solos argilosos, terminando em amplo vale, com solos arenosos. Foram abertas seis trincheiras e feitas seis tradagens em várias profundidades para caracterizar os solos, seus horizontes e as relações existentes entre eles ao longo da encosta. Os perfis foram descritos, segundo a notação adotada pelo CNPS (EMBRAPA, 1988) e amostrados para análises físicas, químicas, mineralógicas e micromorfológicas. Foram coletadas ainda amostras de rochas encontradas no topo da colina e no fundo do vale. Uma representação esquemática da cobertura pedológica da área estudada, é apresentada na Figura 1.

As amostras coletadas para análises físicas, químicas e mineralógicas foram secas ao ar e passadas em peneiras de $2 \mathrm{~mm}$ de malha (T.F.S.A.). O método empregado na análise granulométrica do solo foi o utilizado pela pela EMBRAPA (1979), usando-se $\mathrm{NaOH}$ $1 \mathrm{~N}$ como dispersante.

Foi feito o ataque sulfúrico segundo método descrito por Vettori (1969), modificado por EMBRAPA (1997), utilizando-se $\mathrm{H}_{2} \mathrm{SO}_{4}$ 1:1. Os elementos do complexo sortivo e o carbono orgânico dos solos foram determinados empregando-se metodologia descrita por Vettori (1969), com modificação de EMBRAPA (1997). Cálcio, magnésio e alumínio trocáveis foram extraídos com $\mathrm{KCl} 1 \mathrm{~N}$. A extração do fósforo e do potássio foi feita com solução contendo $\mathrm{H}_{2} \mathrm{SO}_{4}+\mathrm{HCl} 0,050 \mathrm{~N}$. A extração do hidrogênio e do alumínio foi feita com acetato de cálcio $1 \mathrm{~N}$ a pH 7,0. $\mathrm{O} \mathrm{pH}$ foi determinado utilizando-se relação solo/água e relação solo $\mathrm{KCl}$ de 1:2.5. Os óxidos de ferro e de alumínio "livres" foram extraídos com citrato-bicarbonato-ditionito de sódio, conforme Jackson (1973), sendo determinados através da espectroscopia de plasma. As formas menos cristalinas de óxidos de ferro e de alumínio foram extraídas com oxalato de ferro e de alumínio foram extraídas com oxalato de amônio ácido, conforme McKeague \& Day (1966), sendo determinados através da espectroscopia de plasma.

Foram feiras análises mineralógicas qualitativas em amostras de areia e argila, segundo Jackson (1973), consistindo de pré-tratamentos para eliminação de matéria orgânica e dos óxidos de ferro"livres". Amostras da fração argila foram saturadas com potássio e com magnésio, e posteriormente montadas em lâmina orientada (esfregaço), e submetidas à difratometria de raios X. Para tal, utilizou-se um aparelho Rigaku, equipado com tubo de $\mathrm{Cu}$ e filtro de $\mathrm{Ni}$, operando com $20 \mathrm{~mA}$ e $40 \mathrm{Kw}$. Foram obtidos difratogramas das amostras saturadas com $\mathrm{K}^{+}$a $25^{\circ} \mathrm{C}$ e aquecidas a $350^{\circ} \mathrm{C}$ e $550^{\circ} \mathrm{C}$ por duas horas, e das saturadas com $\mathrm{Mg}^{++}$ao

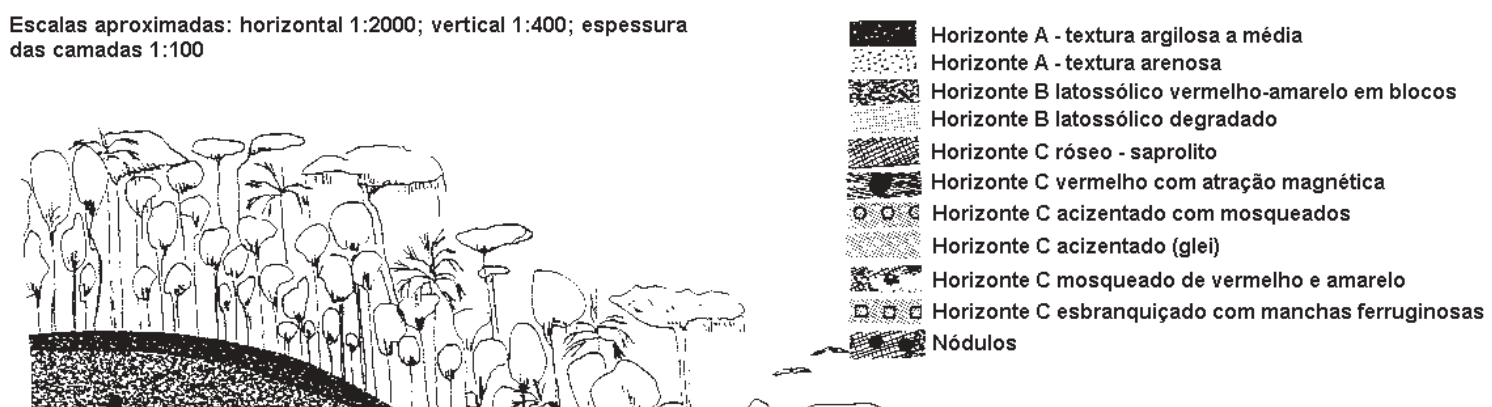

E... Horizonte A - textura argilosa a média A Horizonte A - textura arenosa

1) Horizonte B latossólico vermelho-amarelo em blocos

tu. Horizonte B latossólico degradado

370 Horizonte C róseo - saprolito

it Horizonte $\mathrm{C}$ vermelho com atração magnética

$0 \%$ Horizonte $C$ acizentado com mosqueados

औ४२ Horizonte C acizentado (glei)

ito Horizonte $C$ mosqueado de vermelho e amarelo

D. 0.0 Horizonte $C$ esbranquiçado com manchas ferruginosas Eutédulos

Figura 1: Representação esquemática dos perfis de solos ao longo da sequência estudada.

Figure 1: Schematic representation of the soils profiles along the studied sequence. 
natural e glicolada, no intervalo e de 3 a $42^{\circ} 2$. A interpretação dos difratogramas de raios $\mathrm{X}$ foi feita segundo Brindley \& Brown (1980).

As amostras para análise micromorfológica foram coletadas em caixas plásticas, observando-se a posição e orientação no perfil do solo. No laboratório, foram secas ao ar e, posteriormente, em estufa a $40^{\circ} \mathrm{C}$, durante 4 dias. Na impregnação das amostras utilizou-se uma mistura de suas partes de resina Polylite T-208 para uma de monômero de estireno e 1 gota de catalizador (peróxido de metil-etil-acetona) para cada $100 \mathrm{ml} \mathrm{da}$ mistura. As amostras foram submetidas a vácuo, e terminada a impregnação, as amostras foram retiradas do dessecador e deixadas em repouso à temperatura ambiente por um período de 10 dias, até a completa polimerização e endurecimento. Foram obtidas seções delgadas, as quais foram examinadas em microscópio petrográfico, com polarizador, seguindo-se recomendações de Brewer (1976) e Fitzpatrick (1993).

\section{RESULTADOS E DISCUSSÃO}

\section{Características morfológicas}

Foram identificados morfologicamente 12 horizontes distintos ao longo dos perfis da seqüência. (Quadro 1). Do topo ao terço médio, a encosta é dominada por material latossólico. O perfil 1 é representativo das partes elevadas da colina. Consta de um horizonte A moderado, seguido de um horizonte B latossólico de cor amarelada, sobre um horizonte B latossólico de cor avermelhada. O horizonte Bw amarelado apresenta estrutura moderada, em blocos subangulares, pequenos e médios. A textura dos horizontes A e Bw é argilosa. Entre os horizontes Bw amarelado e Bw avermelhado existe uma camada nodular, formada por nódulos arredondados, de cor violácea, conservando a estrutura de rocha. $\mathrm{O}$ tamanho dos nódulos varia de 1 a $5 \mathrm{~cm}$ de diâmetro e estes ocupam mais de $60 \%$ do volume da camada. O regolito é vermelho, de textura franco argilosa e apresenta considerável atração magnética.

O terço inferior da encosta é caracterizado pela presença de material plíntico sob material latossólico. O perfil 2 é representativo dessa porção da encosta. Consta de um horizonte A moderado, seguido de um horizonte Bw amarelado semelhante ao das partes mais elevadas, de espessura mais reduzida, sobre horizonte plíntico. Abaixo, encontra-se um horizonte $\mathrm{C}$ amarelado com mosqueados vermelhos, seguido de um horizonte $\mathrm{C}$ de cor esbranquiçada com mosqueamento bege pálido. Na base do horizonte $\mathrm{Bw}$ há uma linha de nódulos semelhantes aos encontrados no topo da colina.

Entre o terço inferior e o fundo do vale o material latossólico apresenta características diferenciadas do topo e meia encosta. A espessura é reduzida e a estrutura é de aspecto maciço, com microagregados muito estáveis. O material plíntico dá lugar a materiais

Quadro 1: Composição granulométrica (\%), IF (\%), relação silte/argila e relação areia fina/areia grossa, dos perfis estudados.

Table 1: Granulometric Composition, Flocculation index, silt/clay and coarse sand/fine ratios of the profiles.

\begin{tabular}{|c|c|c|c|c|c|c|c|}
\hline \multirow[t]{2}{*}{ Horizonte } & \multirow{2}{*}{$\begin{array}{l}\text { Profundidade } \\
\qquad \mathrm{cm}\end{array}$} & \multicolumn{4}{|c|}{ Frações (mm) } & \multirow{2}{*}{$\begin{array}{c}\text { Argila } \\
\text { dispersa } \\
\text { em água }(\%)\end{array}$} & \multirow{2}{*}{$\begin{array}{l}\text { IF } \\
(\%)\end{array}$} \\
\hline & & $\begin{array}{c}\text { Areia Grossa } \\
(2-0.20)\end{array}$ & $\begin{array}{l}\text { Areia Fina } \\
(020-0.05)\end{array}$ & $\begin{array}{c}\text { Silte } \\
(0.05-0.002)\end{array}$ & $\begin{array}{c}\text { Argila Total } \\
(<0.002)\end{array}$ & & \\
\hline \multicolumn{8}{|c|}{ Perfil 1 - Latossolo Vermelho Amarelo } \\
\hline$A$ & $0-30$ & 5.0 & 18.0 & 17.0 & 60.0 & 20.0 & 67 \\
\hline Bw1 & $30-140$ & 4.0 & 15.0 & 9.0 & 72.0 & 3.0 & 96 \\
\hline 2Bwc & $140-190$ & 7.0 & 12.0 & 11.0 & 70.0 & 3.0 & 96 \\
\hline 2Bw2 & $190-320$ & 5.0 & 15.0 & 7.0 & 63.0 & 3.0 & 95 \\
\hline $2 \mathrm{C}$ & & 2.0 & 23.0 & 38.0 & 37.0 & 3.0 & 92 \\
\hline \multicolumn{8}{|c|}{ Perfil2 - Latossolo Vermelho Amarelo intergrade para Podzólico plíntico } \\
\hline A & $0-20$ & 27.0 & 37.0 & 8.0 & 28.0 & 2.0 & 93 \\
\hline Bw & $20-75$ & 9 & 33.0 & 13.0 & 45.0 & 17.0 & 62 \\
\hline $\mathrm{Bf}$ & $75-130$ & 7.0 & 20.0 & 14.0 & 59.0 & 3.0 & 95 \\
\hline $\mathrm{Cg} 1$ & $130-180$ & 5.0 & 25.0 & 21.0 & 49.0 & 3.0 & 94 \\
\hline $\mathrm{Cg} 2$ & & 2.0 & 15.0 & 47.0 & 36.0 & 0.0 & 100 \\
\hline \multicolumn{8}{|c|}{ Perfil 3 - Podzólico plíntico intergrade para Latossolo Vermelho Amarelo } \\
\hline A & $0-20$ & 18.0 & 52.0 & 10.0 & 20.0 & 4.0 & 80 \\
\hline Bw & $20-45$ & 14.0 & 42.0 & 15.0 & 29.0 & 12.0 & 59 \\
\hline $\mathrm{Bf}$ & $45-70$ & 15.0 & 35.0 & 12.0 & 38.0 & 3.0 & 92 \\
\hline $\mathrm{Cg} 1$ & $70-100$ & 24.0 & 27.0 & 18.0 & 31.0 & 3.0 & 90 \\
\hline $\mathrm{Cg} 2$ & & 5.0 & 34.0 & 40.0 & 21.0 & 0.0 & 100 \\
\hline \multicolumn{8}{|c|}{ Perfil 4 - Areia Quartzosa Hidromórfica } \\
\hline A & $0-30$ & 13.0 & 57.0 & 11.0 & 19.0 & 3.0 & 84 \\
\hline $\mathrm{A} / \mathrm{C}$ & $30-70$ & 19.0 & 52.0 & 11.0 & 18.0 & 3.0 & 83 \\
\hline $\mathrm{Cg} 1$ & $70-100$ & 20.0 & 51.0 & 11.0 & 18.0 & 5.0 & 72 \\
\hline $\mathrm{Cg} 2$ & $100-140$ & 27.0 & 44.0 & 10.0 & 19.0 & 7.0 & 63 \\
\hline $\mathrm{Cg} 3$ & & 7.0 & 44.0 & 25.0 & 24.0 & 8.0 & 67 \\
\hline
\end{tabular}


gleizados. Os perfis 3 e 4 representam essa parte transicional da seqüência. $\mathrm{O}$ perfil 4 é composto de um horizonte A moderado, seguido de um horizonte $\mathrm{A} / \mathrm{C}$ amarelado, passando por um horizonte $\mathrm{C}$ gleizado e abaixo, um horizonte $\mathrm{C}$ esbranquiçado. $\mathrm{Na}$ profundidade de 1 metro, foi encontrada uma concentração de material grosseiro, com fragmentos angulosos de quartzo, de 1 a $5 \mathrm{~cm}$ de diâmetro. A textura dos horizontes desse perfil é franco-arenosa, excetuando-se o horizonte $\mathrm{C}$ mais profundo que é franco-argilo-arenoso.

A colina termina em um fundo de vale arenoso, alagado. Com auxílio de um trado foi identificado um horizonte A moderado, sobre horizontes $\mathrm{C}$ arenosos, compostos de areia de quartzo esbranquiçada, gleizados. A aproximadamente 1 metro de profundidade, foi identificada uma concentração de material areno-quartzoso mais grosseiro.

\section{Características físicas}

Os solos das partes elevadas da encosta até o terço médio, representados pelo perfil 1, são muito argilosos; os solos da região de transição, representados pelos perfis 2 e 3, são de textura média/argilosa: no fundo do vale os solos apresentam textura média (perfil 4) passando a arenosa . O Quadro 2 mostra a distribuição das frações areia, silte e argila por camada, ao longo da seqüência. Analisados nesse sentido, os dados mostram uma redução gradativa nos teores de argila, do topo da colina para o fundo do vale. Essa redução se acentua onde o hidromorfismo se intensifica. Tal constatação sugere um processo de ferrólise, destruindo plasma argiloso (Brinkman, 1970).

Os teores de silte se mantêm relativamente constantes ao longo da seqüência, com exceção das camadas mais profundas das partes elevadas da encosta, onde eles são mais elevados (perfil $1 \mathrm{em}$ domínio latossólico). A fração silte apresenta uma distribuição normal, aumentando em profundidade, exceto na parte mais baixa da seqüência (por tradagem), onde a variação é pequena. Os teores de areia aumentam ao longo da seqüência, acompanhando a redução dos teores de argila (Figura 2).

O Índice de Floculação (IF) é mais elevado no material do topo da encosta, onde há maiores concentrações de óxidos. Existem mais estudos mostrando a influência dos óxidos de ferro e de alumínio na floculação dos materiais argilosos dos solos. A maior estabilidade dos agregados é proporcionada mais pelo grau de anisotropia provocado pelos óxidos de ferro, do que pelo próprio conteúdo (Uehara et al., 1962; Cagauan \& Uehara, 1965; Schwertmann \& Taylor , 1977).

A relação silte/argila pode ser usada para caracterizar o processo de translocação: nos horizontes eluviais a relação é maior do que nos iluviais (Lepsch, 1975). Van Wambeke (1962) propôs o uso da relação silte/argila para separar solos altamente intemperizados de solos mais jovens. O Sistema Brasileiro de Classificação de Solos utiliza o valor 0,7 nos solos de textura média e 0,6 nos solos de textura argilosa dessa relação, para separar latossolos de cambissolos (EMBRAPA, 1988). Essa relação, no entanto, deve ser vista com cuidado, pois em certos casos a fração silte é constituída de flocos de caulinita, o que não significa estágio pouco avançado de intemperismo (Gomes, 1976; Rezende, 1980; Schaefer, 1995).

A relação silte/argila apresenta valores baixos $(<$

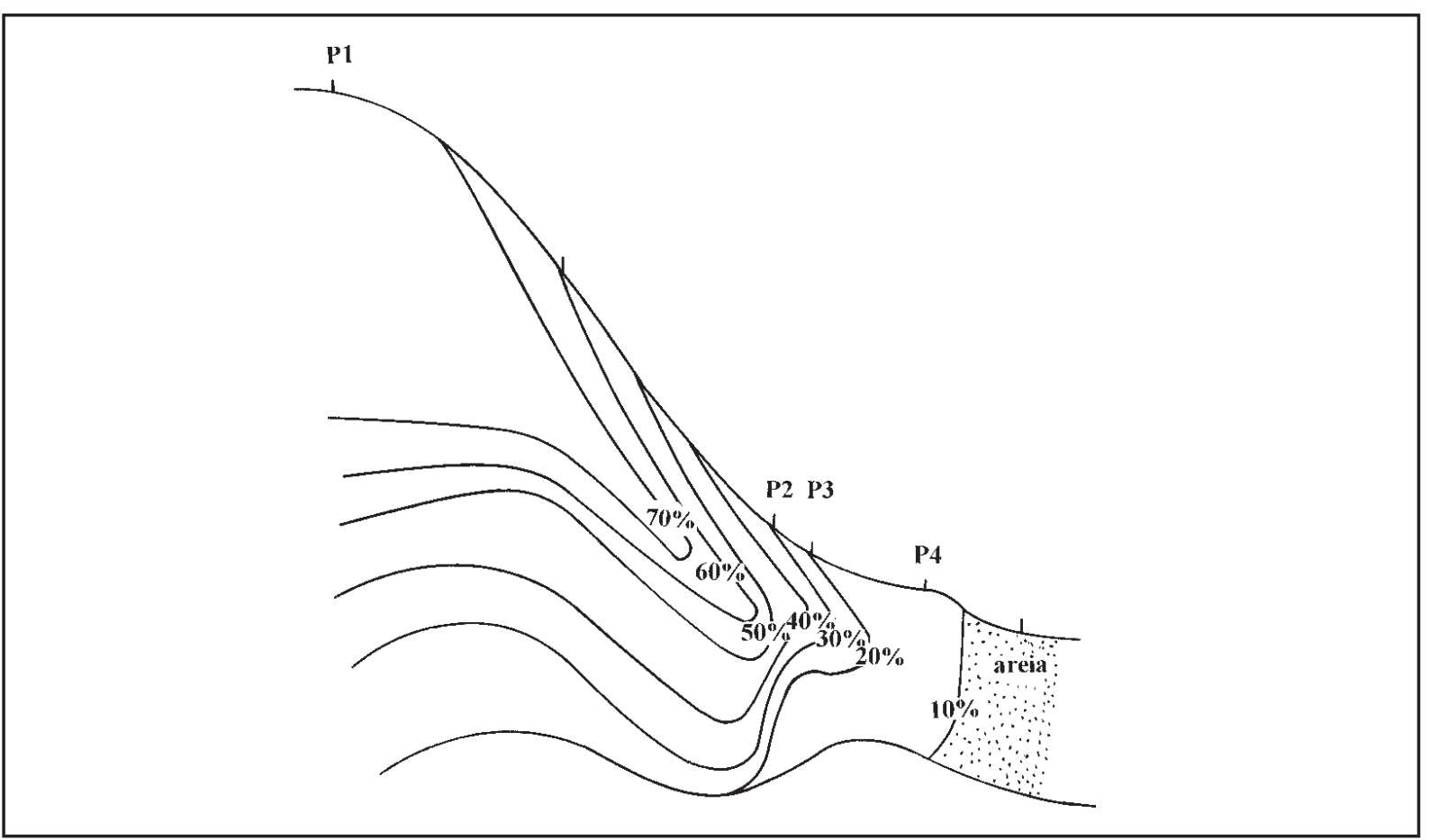

Figura 2: Variações relativas dos teores de argila e areia ao longo da seqüência estudada.

Figure 2: Relative variation of clay and sand along the studied sequence. 
0,7) nos horizontes $\mathrm{A}, \mathrm{Bw}_{1}, 2 \mathrm{Bwc}, 2 \mathrm{Bw} 2$, $\mathrm{Bf}$ e $\mathrm{Cg} 1$ ao longo da encosta (todos os perfis), o que segundo Van Wambeke (1962), caracteriza materiais de solos altamente intemperizados. Os valores dessa relação são mais elevados $(>1,0)$ nas partes mais baixas dos perfis (horizontes $\mathrm{C}$ e $\mathrm{Cg} 2$ ).

A relação areia fina/areia grossa tem sido utilizada para estudos de homogeneidade nos materiais de origem do solo. Em materiais homogêneos a relação se mantém uniforme ao longo do perfil, e onde há descontinuidade litológica a relação também se altera (Tyler et al., 1962; Barshad, 1964; Ribeiro, 1980).

Os dados das relações silte/argila e areia fina/areia grossa mostram uma grande variação em profundidade, em todos os pontos da seqüência, conforme mostram o Quadro 2 e Figura 2. Há grande semelhança entre as curvas das duas relações, o que sugere que as variações em profundidade são mais devidas à heterogeneidade do material de origem, do que a perdas ou ganhos relativos.

A relação areia fina/areia grossa também no sentido lateral mostra irregularidade conforme demonstra a Figura 2, refletindo variações no material de origem também neste sentido.

\section{Características químicas e carbono orgânico}

Da encosta ao fundo do vale, os solos apresentam elevada acidez, com pH em água variando de 4.7 a 5.6 no perfil $1,4.6$ a 5.5 no perfil $2,5.1$ a 5.5 nos perfis 3 e 4. A CTC é baixa, com: valores abaixo de $4.0 \mathrm{cmol} . \mathrm{dm}-$ 3, para a fração mineral. A contribuição da matéria orgânica é fator destacado nesse sistema, dobrando ou até triplicando os valores da CTC no horizontes superficiais.

Os solos apresentam grande pobreza em bases trocáveis, com valores $\mathrm{V}<10 \%$ nas partes elevadas da seqüência e na superfície dos perfis das partes mais baixas. Há um pequeno acréscimo da saturação de bases em profundidade na região de transição (hor. $\mathrm{Bf}, \mathrm{Cg} 1$, $\mathrm{Cg} 2$ do perfil 3) e no fundo do vale (hors. $\mathrm{Cg} 1, \mathrm{Cg} 2 \mathrm{e}$ $\mathrm{Cg} 3$ do perfil 4), provavelmente devido à adição de algumas bases via fluxo lateral ou menor remoção relativa (Moniz et al., 1982). Apresentam elevada saturação de alumínio, sendo solos álicos em toda a seqüência, com saturação de alumínio acima de $60 \%$, chegando a $88 \%$.

$\mathrm{O} \Delta \mathrm{pH}$ é negativo em toda a seqüência, caracterizando solos eletronegativos. A baixa CTC e o

Quadro 2: Características químicas dos perfis estudados

Table: chemical characteristics of the stuied soils.

\begin{tabular}{|c|c|c|c|c|c|c|c|c|c|c|c|}
\hline \multirow[t]{3}{*}{ Horizonte } & \multirow{3}{*}{$\begin{array}{l}\text { Profundi- } \\
\text { dade-cm }\end{array}$} & & & \multirow{3}{*}{$\mathrm{DpH}$} & \multicolumn{7}{|c|}{$\mathrm{cmol}_{\mathrm{c} \cdot} \cdot \mathrm{dm}^{-3}$} \\
\hline & & \multicolumn{2}{|c|}{$\mathrm{pH}(1: 2.5)$} & & \multicolumn{5}{|c|}{ Valor } & \multicolumn{2}{|c|}{ CTC } \\
\hline & & $\mathrm{H}_{2} \mathrm{O}$ & Kcl $1 \mathrm{~N}$ & & $\mathrm{Ca}^{++}$ & $\mathrm{Mg}^{++}$ & $\mathrm{K}^{+}$ & $s$ & $\mathrm{Al}^{+++}$ & $\mathrm{H}^{+}$ & $(\mathrm{pH} 7.0)$ \\
\hline \multicolumn{12}{|c|}{ Perfil 1 - Latossolo Vermelho Amarelo } \\
\hline $\mathrm{A}$ & $0-30$ & 4.7 & 4.1 & -0.6 & 0.3 & 0.1 & 0.05 & 0.45 & 2.1 & 5.8 & 8.4 \\
\hline Bw1 & $30-140$ & 5.3 & 4.6 & -0.7 & 0.1 & 0.1 & 0.01 & 0.21 & 0.5 & 2.4 & 3.1 \\
\hline 2Bw2 & $190-320$ & 5.5 & 4.6 & -0.9 & 0.1 & 0.1 & 0.01 & 0.21 & 0.6 & 2.3 & 3.1 \\
\hline $2 \mathrm{C}$ & $320-400^{+}$ & 5.6 & 4.6 & -1.0 & 0.2 & 0.1 & - & 0.30 & 1.0 & 2.2 & 3.5 \\
\hline \multicolumn{12}{|c|}{ Perfil 2 - Latossolo Vermelho Amarelo intergrade para Podzólico Plintico } \\
\hline A & $0-20$ & 4.6 & 3.9 & -0.7 & 0.4 & 0.1 & 0.12 & 0.62 & 1.7 & 8.1 & 10.4 \\
\hline Ew & $20-75$ & 49 & 43 & -0.6 & 0.2 & 0.1 & 0.02 & 0.32 & 1.3 & 2.7 & 4.3 \\
\hline $\mathrm{Bf}$ & $75-130$ & 5.5 & 4.4 & -1.1 & 0.1 & 0.1 & 0.01 & 0.21 & 0.8 & 2.1 & 3.1 \\
\hline Cg1 & $130-180$ & 5.5 & 43 & -1.2 & 0.1 & 0.1 & 0.01 & 0.21 & 1.2 & 2.0 & 3.4 \\
\hline $\mathrm{Cg} 2$ & $180-240^{+}$ & 5.2 & 4.1 & -1.1 & 0.2 & 0.1 & 0.01 & 0.31 & 2.3 & 2.2 & 4.8 \\
\hline \multicolumn{12}{|c|}{ Perfil 3 - Podzólico Plíntico intergrade para Latossolo Vermelho Amarelo } \\
\hline A & $0-20$ & 5.4 & 4.6 & -0.8 & 0.1 & 0.1 & 0.05 & 0.25 & 0.9 & 3.6 & 4.8 \\
\hline Ew & $20-45$ & 5,4 & 4.5 & -0.9 & 0.1 & 0.1 & 0.02 & 0.22 & 0.9 & 2.0 & 3.1 \\
\hline $\mathrm{Bf}$ & $45-70$ & 5.1 & 4.4 & -0.7 & 0.2 & 0.1 & 0.02 & 0.32 & 0.7 & 1.8 & 2.6 \\
\hline Cg1 & $70-100$ & 5.1 & 4.2 & -0.9 & 0.2 & 0.1 & 0.01 & 0.31 & 0.9 & 1.2 & 2.4 \\
\hline $\mathrm{Cg} 2$ & $100-140^{+}$ & 5.5 & 41 & -1.4 & 0.5 & 0.2 & 0.02 & 0.72 & 1.4 & 1.2 & 3.3 \\
\hline \multicolumn{12}{|c|}{ Perfil 4 - Areia Qualtzosa Hidromórfica } \\
\hline A & $0-30$ & 54 & 4.6 & -0.8 & 0.2 & 0.1 & 0.05 & 035 & 0.6 & 3.0 & 4.0 \\
\hline $\mathrm{A} / \mathrm{C}$ & $30-70$ & 5.4 & 4.5 & -0.9 & 0.2 & 0.1 & 0.02 & 0.32 & 0.7 & 2.5 & 3.5 \\
\hline $\mathrm{Cg} 1$ & $70-100$ & 5.1 & 4.4 & -0.7 & 0.3 & 0.1 & 0.02 & 0.42 & 0.8 & 1.3 & 2.5 \\
\hline $\mathrm{Cg} 2$ & $100-140$ & 5.1 & 4.2 & -0.9 & 0.1 & 0.1 & 0.02 & 0.22 & 1.1 & 0.8 & 2.1 \\
\hline $\operatorname{Cg} 3$ & $140-150^{*}$ & 5.5 & 4.1 & -1.4 & 0.5 & 0.9 & 0.04 & 1.44 & 1.7 & 1.9 & 5.0 \\
\hline
\end{tabular}


$\Delta \mathrm{pH}$ negativo são características de solos com mineralogia caulinítica. Segundo Mekaru \& Uehara (1972), nos sistemas dominados por argilominerais 1:1, o $\Delta \mathrm{pH}$ é sempre negativo.

Há variação dos teores de carbono em profundidade e ao longo da seqüência (Quadro 1). Estes atingem valores acima de $3 \%$ na superfície dos perfis, do topo até o sopé da encosta. Diminui para $2 \%$ nas partes mais baixas, onde o hidromorfismo é mais acentuado e os solos se tornam mais arenosos. Nos primeiros $10 \mathrm{~cm}$, a porcentagem de carbono decresce para aproximadamente $1 \%$, chegando com esse valor até $60 \mathrm{~cm}$ de profundidade.

\section{Dinâmica de $\mathrm{SiO}_{2}, \mathrm{Al}_{2} \mathrm{O}_{3}$ e $\mathrm{Fe}_{2} \mathrm{O}_{3}$}

A dinâmica dos principais componentes da fração argila do solo, pode ser compreendida através do estudo de sua distribuição ao longo dos perfis e das seqüências.

Através da extração pelo ataque sulfúrico, foram obtidos os teores totais de $\mathrm{SiO}_{2}, \mathrm{Al}_{2} \mathrm{O}_{3}$ e $\mathrm{Fe}_{2} \mathrm{O}_{3}$ (Quadro
3) ao longo da seqüência. Os dados evidenciam que o material de origem é heterogêneo, pois a distribuição em profundidade de $\mathrm{SiO}_{2}, \mathrm{Al}_{2} \mathrm{O}_{3}$ e $\mathrm{Fe}_{2} \mathrm{O}_{3}$ é irregular ao longo da sequência.

No horizonte $\mathrm{C}$ do perfil 1 , situado na meia encosta é influenciado por rocha máfica $\left(20 \%\right.$ de $\left.\mathrm{Fe}_{2} \mathrm{O}_{3}\right)$, mas o horizonte $\mathrm{B}$ latossólico vermelho pode também receber influência desse material $\left(14 \%\right.$ de $\left.\mathrm{Fe}_{2} \mathrm{O}_{3}\right)$. Há uma tendência à diminuição de $\mathrm{SiO}_{2}, \mathrm{Al}_{2} \mathrm{O}_{3}$ e $\mathrm{Fe}_{2} \mathrm{O}_{3}$ em dois sentidos: na superfícies e lateralmente, ao longo da seqüência. Esta diminuição é gradual e se acentua na região de atuação do hidromorfismo. Do ponto de vista mineralógico, há um domínio inferido de mineralogia caulinítica não oxídica em toda a seqüência: valores de Ki entre 1.6 e 1.9 ; Kr entre 1.13 e 1.169.

\section{Grau de cristalinidade dos óxidos de ferro e de alumínio}

Uma das maneiras de se estimar o grau de

Quadro 3: Silício, ferro e alumínio extraídos pelo ataque sulfúrico; ferro e alumínio extraídos pelo CBD e pelo oxalato de amônio. Resultados expressos em dag $\mathrm{kg}^{-1}$.

Table 3: Silica, irm and alumoinium extracted by the sulphuric atack; iron and aluminium extracted by dithionite-citrate and amonium-oxalate; expressed in dag $\mathrm{kg}^{-1}$.

\begin{tabular}{|c|c|c|c|c|c|c|c|c|c|c|}
\hline \multirow[t]{2}{*}{ Horizonte } & \multirow[t]{2}{*}{$\begin{array}{l}\text { Profundi- } \\
\text { dade-cm }\end{array}$} & \multicolumn{3}{|c|}{ Ataque com $\mathrm{H}_{2} \mathrm{SO}_{4}$} & \multicolumn{2}{|c|}{ CBD } & \multicolumn{2}{|c|}{$\begin{array}{c}\text { Ox. de } \\
\text { Amônio }\end{array}$} & \multirow{2}{*}{$\begin{array}{l}\text { Ferro } \\
\text { 'Ativo" }\end{array}$} & \multirow{2}{*}{$\begin{array}{l}\text { Aluminio } \\
\text { "Ativo" }\end{array}$} \\
\hline & & $\mathrm{SiO}_{2}$ & $\mathrm{Fe}_{2} \mathrm{O}_{3}$ & $\mathrm{Al}_{2} \mathrm{O}_{3}$ & $\mathrm{Fe}_{2} \mathrm{O}_{3}$ & $\mathrm{Al}_{2} \mathrm{O}_{3}$ & $\mathrm{Fe}_{2} \mathrm{O}_{3}$ & $\mathrm{Al}_{2} \mathrm{O}_{3}$ & & \\
\hline \multicolumn{11}{|c|}{ Perfil 1 - Latossolo Vermelho Amarelo } \\
\hline A & $0-30$ & 24.2 & 10.2 & 23.4 & 9.27 & 3.17 & 0.79 & 1,44 & 0.09 & 0.45 \\
\hline Bw1 & $30-140$ & 26.8 & 10.1 & 24.7 & 9.60 & 3.10 & 0.41 & 1.55 & 0.04 & 0.50 \\
\hline 2Bw2 & $190-320$ & 29.7 & 13.9 & 28.8 & 12.73 & 2.13 & 0.16 & 1.34 & 0.01 & 0.63 \\
\hline $2 \mathrm{C}$ & $320-400^{+}$ & 29.1 & 20.3 & 27.8 & 23.47 & 3.25 & 0.11 & 1.34 & - & 041 \\
\hline \multicolumn{11}{|c|}{ Perfil 2 - Latossolo Vermelho Amarelo intergrade para Podzólico Plíntico } \\
\hline A & $0-20$ & 95 & 2.9 & 9.4 & 653 & 2.19 & 1.16 & 0.35 & 0.18 & 0.93 \\
\hline Ew & $20-75$ & 27.0 & 4.8 & 15.5 & 6.81 & 2.34 & 0.50 & 0.93 & 0.07 & 0.40 \\
\hline Ef & $75-130$ & 29.1 & 6.0 & 26.0 & 6.09 & 1.57 & 0.24 & 1.15 & 0.04 & 0.73 \\
\hline $\mathrm{Cg} 1$ & $130-180$ & 16.7 & 5.0 & 25.0 & 4.39 & 1.08 & 0.09 & 0.94 & 0.02 & 0.88 \\
\hline $\mathrm{Cg} 2$ & $180-240^{+}$ & 27.2 & 3.1 & 24.7 & 2.59 & 0.60 & 0.04 & 1.00 & 0.02 & 1.66 \\
\hline \multicolumn{11}{|c|}{ Perfil 3 - Podzólico Plintico intergrade para Latossolo Vermelho Amarelo } \\
\hline A & $0-20$ & 7.8 & 1.8 & 8.1 & 5.14 & 1.61 & 1.37 & 1,42 & 0.27 & 0.88 \\
\hline Bw & $20-45$ & 12.1 & 2.4 & 10.7 & 4.96 & 1.51 & 0.99 & 0.91 & 0.20 & 0.60 \\
\hline $\mathrm{Bf}$ & $45-70$ & 14.9 & 2.8 & 15.3 & 4.97 & 1.51 & 0.54 & 0.96 & 0.11 & 0.64 \\
\hline $\mathrm{Cg} 1$ & $70-100$ & 17.9 & 2.5 & 17.8 & 2.90 & 0.89 & 0.06 & 0.09 & 0.02 & 0.10 \\
\hline $\mathrm{Cg} 2$ & $100-140^{+}$ & 22.8 & 2.0 & 21.2 & - & - & - & - & - & - \\
\hline \multicolumn{11}{|c|}{ Perfil 4 - Areia Quartzosa Hidromórfica } \\
\hline A & $0-30$ & 6.3 & 1.1 & 7.9 & 2.43 & 2.10 & 1.40 & 3,38 & 0.58 & 1.61 \\
\hline $\mathrm{A} / \mathrm{C}$ & $30-70$ & 5.2 & 1.1 & 7.1 & 2.31 & 1.15 & 1.63 & 1.87 & 0.70 & 1.62 \\
\hline Cg1 & $70-100$ & 6.3 & 1.1 & 7.4 & 1.90 & 0.57 & 1.33 & 1.30 & 0.70 & 2.28 \\
\hline $\mathrm{Cg} 2$ & $100-140$ & 7,4 & 0.9 & 8.1 & 1.87 & 0.38 & 0.56 & 1.15 & 0.30 & 3.03 \\
\hline $\operatorname{Cg} 3$ & $140-150^{+}$ & 12.1 & 0.8 & 7.9 & - & - & - & - & - & - \\
\hline
\end{tabular}


cristalinidade dos óxidos é através da relação entre os extratores citrato-bicarbonato-ditionito de sódio (CBD) e o oxalato de amônio. Blume \& Schwertmann (1969) mostraram que é possível de se fazer uma caracterização de grandes grupos de solos, através do perfil de distribuição dos óxidos de alumínio, de ferro e de manganês, usando os dos extratores, as relações entre eles, bem como a relação entre os extratores e os teores de argila.

No Brasil, vários trabalhos têm sido conduzidos utilizando-se as extrações com CBD e com oxalato de amônio ácido na determinação de formas "livres" e menos cristalinas de ferro e de alumínio (Potter \& Kämpf, 1983; Gualberto et al., 1987).

O Quadro 3 apresenta os dados de extração de ferro e alumínio com CBD e com oxalato de amônio. Os dados da extração com CBD evidenciam uma distribuição semelhante aquela mostrada pelo ataque sulfúrico: teores mais elevados de óxidos de ferro e de alumínio nas partes mais altas da encosta, reduzindo nas partes mais baixas.

Os dados da extração com oxalato de amônio mostram resultado inverso. Os teores extraídos dos dois elementos, bem como a relação entre as formas extraídas pelos dois extratores, aumentam do topo para o fundo do vale. Esses resultados refletem maior grau de cristalinidade dos compostos de ferro e de alumínio no material latossólico da encosta. Esses óxidos se tornam menos cristalinos e são removidos do solo à medida que se caminha para as partes baixas do vale, onde o hidromorfismo se acentua.

As variações nos teores de ferro e de alumínio encontradas em profundidade (aumento no perfil $1 \mathrm{e}$ diminuição nos demais), são devidas à maior concentração de ferro e de alumínio no material de origem do horizonte $\mathrm{C}$ do perfil 1 , e ao aumento de intensidade do hidromorfismo em profundidade, na parte baixa da seqüência, favorecendo a remoção.

As relações entre os teores dos elementos e a fração argila não mostram sinais de concentração relativa, significando que esses elementos sofrem remoção sumária do solo (verticalmente e lateralmente). O perfil de distribuição das várias formas de óxidos de ferro e de alumínio corrobora o encontrado em outros estudos (McKeague \& Day, 1966; Blume \& Schwertmann, 1969; Kampf, 1988; Kamf \& Schwertmann, 1983; Kampf et al., 1988; Schwertmann \& Taylor, 1989). Os dados concordam que:

-a razão de atividade $\left(\mathrm{Fe}_{\mathrm{ox}} / \mathrm{Fe}_{\mathrm{CBD}}, \mathrm{Al}_{\mathrm{ox}} / \mathrm{Al}_{\mathrm{cbd}}\right)$, geralmente decresce em profundidade no solo, indicando que existe uma maior proporção de óxidos "livres" nas formas mais cristalinas na sub-superfície que na superfície do solo, ou seja, o maior teor de compostos orgânicos próximo à superfície atua como inibidor da cristalização dos óxidos.

-a razão de atividade também é influenciada por diferenças no regime de umidade, em diferentes perfis ao longo de uma toposseqüência. Solos bem drenados, das partes elevadas, apresentam menor razão de atividade que solos hidromórficos, das partes mais baixas na paisagem. As sucessivas transformações do Fe (II) em Fe (III) e vice-versa (Van Breemen, 1988) em solos sazonalmente muito úmidos podem explicar este aspecto, no tocante ao ferro.

-a quantidade total de óxidos pode ser influenciada pelo tipo de material de origem: solos desenvolvidos de materiais com influência de rochas máficas (perfil 1) contêm teores mais elevados que solos derivados de rochas de natureza mais ácida (os demais).

\section{Mineralogia da fração argila}

A mineralogia da fração argila dos solos estudados foi caracterizada através da difração de raios X ). A mineralogia da fração argila da seqüência estudada é relativamente simples. Há um domínio de caulinita em todos os perfis, reconhecida pelos picos nas regiões de $7.25,3.57$ e 2.39. Esses picos desaparecem nas amostras aquecidas a $550^{\circ} \mathrm{C}$ (Andrade, 1990). Acompanhando a caulinita, foram identificadas argilas do grupo das micas e vermiculitas-cloritizadas. No horizonte B latossólico de cor avermelhada foi identificada também a gibbsita, cujos picos aparecem nas regiões de $4.85 \AA$ e $4.37 \AA$. Os picos das micas foram mais intensos nas partes inferiores dos perfis. A vermiculita-cloritizada está presente principalmente nos horizontes mais superficiais, à exceção do perfil 4. A composição mineralógica da fração argila dos solos estudados é a mais comumente encontrada em solos tropicais. Trabalhos relacionados a solos da Amazônia Brasileira mostram, como constituintes principais da fração argila, a caulinita e os óxidos de ferro na $\mathrm{s}$ mais diversas formas. Como minerais acessórios aparecem a muscovita, vermiculitacloritizada e a vermiculita.

A distribuição das micas e dos minerais cloritizados encontrados ao longo dos perfis, é a mais comum de se esperar. Segundo Fanning \& Keramidas (1977), as micas são mais encontradas em profundidade nos solos porque a maior parte delas parece ser herdada dos materiais de origem. Com uma maior intensidade de intemperismo nos horizontes superficiais, elas se alteram.

\section{Características micromorfológicas}

Para uma visualização das características micromorfológicas em escala $1: 1$, foram montadas as fotografias de seções finas ao longo da sequência, evidenciando as principais alterações na côr, na relação plasma/esqueleto e na distribuição de feições pedológicas particulares, tais como nódulos, concreções e fragmentos carbonizados (Figura 3). Foi feita uma caracterização sumária da micromorfologia de segmentos representativos do local estudado, em alguns horizontes selecionados (Quadro 4). Em adição, foram ilustrados aspectos e feições micropedológicas destacadas, em escala microscópica (Figura 4).

No topo da sequência ( $\mathrm{P} 1)$, o horizonte $\mathrm{Bw}_{1}$ evidenciou um plasma vermelho-amarelo, com 
microagregação e presença de estruturas litoreliquiares (nódulos), associados (Figura 4, A). As estruturas em nódulos encerram pseudomorfos de VHE e caulinita, formando flocos de dimensões variadas, fortemente cimentados por precipitados secundários de óxidos de ferro. Essas estruturas se encontram preservadas, sem sinais evidentes de degradação. Em $2 \mathrm{Bwc}_{1}$, o plasma é amarelo claro com domínios vermelho-amarelos semelhantes aos encontrados em $\mathrm{Bw}_{1}$. As litorelíquias nodulares apresentam, contudo, indícios de degradação incipiente, com a presença de um plasma amarelo claro mais pálido, envolvendo-os (Figura 4,B). Domínios massivos são comuns, à semelhança do $\mathrm{Bw}_{1}$, possivelmente em virtude da natureza caulinítica, favorecendo o arranjo face-a-face e coalescência de microagregados (Schaefer et al., 1995).

No perfil 3, tanto em $\mathrm{Bf}$ quanto em $\mathrm{Cg}_{1}$, há uma microestrutura de tendência porfirítica, em vista da concentração relativa do esqueleto quartzoso e clara evidência de destruição de plasma argiloso, na forma de microagregados e nódulos de superfície corrodida, especialmente em Cg1 (Figura 4, C e D). Com a degradação há uma sensível redução do plasma argiloso e do cimento ferruginoso, além da diminuição dos pseudomorfos dispersos. Assim, o fenômeno de ferrólise postulado encontra ampla evidência de uma atuação à nível micropedológico, à exemplo do descrito por Altemuller \& Klinge (1964), Bravard \& Righi
(1991), Benites (1998) e Campos (1998), em solos sujeitos à processos pedogenéticos semelhantes.

Em termos gerais, as principais variações são encontradas nos teores de plasma, que sofre uma redução gradativa do topo da encosta para o fundo do vale; na variação da coloração: vermelho-amarelo/ vermelho escuro no topo da seqüência, bege na região de transição e esbranquiçado no fundo do vale e um concomitante aumento na percentagem do esqueleto.

\section{RESUMO E CONCLUSÕES}

Caracterizou-se e estudou-se a pedogênese de uma seqüência Latossolo Vermelho Amarelo - Podzólico Plíntico - Areia Quartzosa Hidromórfica, desenvolvidos de materiais do Complexo Cristalino Guianense, no Estado do Amazonas. A área de estudo situa-se dentro da reserva indígena Waimiri-Atroari, próximo ao $\mathrm{Km}$ 160 da BR 174, que liga Manaus a Caracaraí, em relevo colinoso, solos argilosos nas partes elevadas, que evoluem lateralmente terminando em amplo vale de fundo arenoso, com forte hidromorfismo. Os regimes de temperatura dos solos são isoipertérmicos e hipertérmicos e os regimes de umidade údico e áquico nas partes mais elevadas e no fundo do vale, respectivamente. Foram descritos 12 perfis, dos quais foram selecionados quatro perfis representativos de três segmentos de seqüência (latossolo, segmento de

Quadro 4: Características micromorfológicas das amostras selecionadas. Table 4: micromorphological characteristics of some selected horizones

\begin{tabular}{|c|c|c|c|c|}
\hline Caracteristica & $\begin{array}{c}\text { P1 Latossolo } \\
\text { Vermelho Amaralo - } \\
\text { Bw1 }\end{array}$ & $\begin{array}{c}\text { P1 Latossolo } \\
\text { Vermelho Amarelo - } \\
\text { 2Bwc1 }\end{array}$ & $\begin{array}{c}\text { P3 Podzólico Plintico } \\
\text { - Bf }\end{array}$ & $\begin{array}{c}\text { P3 Potzolico Plintico } \\
-\mathrm{Cg}^{1}\end{array}$ \\
\hline $\begin{array}{l}\text { Matriz do solo (sob } \\
\text { Iuz plana } \\
\text { polarizada) }\end{array}$ & Isotrópica & $\begin{array}{c}\text { Isotrópica, com zonas } \\
\text { anisotropicas }\end{array}$ & $\begin{array}{c}\text { Silassépica, isotropico } \\
\text { com dominios } \\
\text { anisotrópicos }\end{array}$ & $\begin{array}{c}\text { Silasseppica, isotropico } \\
\text { com dominios } \\
\text { anisotropicos }\end{array}$ \\
\hline Tipo de estrutura & $\begin{array}{l}\text { Granica/granoidica; } \\
\text { Microgranular com } \\
\text { dominios massivos }\end{array}$ & $\begin{array}{l}\text { Granica/gransidica: } \\
\text { microgranular com } \\
\text { dominios massivos }\end{array}$ & $\begin{array}{c}\text { Porfírica + intertéxtica, } \\
\text { massiva }\end{array}$ & $\begin{array}{c}\text { Porfirica + intertéxtica, } \\
\text { massiva }\end{array}$ \\
\hline $\begin{array}{l}\text { Esqueleto } \\
\text { (composiça) }\end{array}$ & Qtzo, pseudomorfos & Qtzo, pseudomorfos & $\begin{array}{l}\text { Qtzo, raros } \\
\text { pseudomorfos }\end{array}$ & QtZo \\
\hline $\begin{array}{l}\text { Porosidade } \\
\text { (aproxim.) }\end{array}$ & $25-30 \%$ & $25 \%$ & $25 \%$ & $30 \%$ \\
\hline Forma dos poros & $\begin{array}{c}\text { Canais } \\
\text { intergranulares, vazios } \\
\text { e fissuras }\end{array}$ & $\begin{array}{c}\text { Canais } \\
\text { intergranulares, vazios } \\
\text { efissuras }\end{array}$ & $\begin{array}{c}\text { Canais irregulares, } \\
\text { intergranulares, } e \\
\text { vazios }\end{array}$ & $\begin{array}{c}\text { Canais irregulares, } \\
\text { intergranulares, } e \\
\text { vazios }\end{array}$ \\
\hline $\begin{array}{l}\text { Estrutura } \\
\text { associada }\end{array}$ & $\begin{array}{l}\text { Nódulos e concresibes } \\
\text { litoreliquiares; } \\
\text { pseudomorfos de mica }\end{array}$ & $\begin{array}{l}\text { Nódulas e concreçoes } \\
\text { litoreliquiares: } \\
\text { pseudomorfos de mica }\end{array}$ & $\begin{array}{l}\text { Nódulos e concreçoes } \\
\text { litoreliquiares; } \\
\text { pseudomorfos de mica } \\
\text { \& microagregados } \\
\text { degradados }\end{array}$ & $\begin{array}{l}\text { Nodulos e concreços } \\
\text { litoreliquiares; } \\
\text { pseudomorfos de mica } \\
\text { e microagregados } \\
\text { degradados }\end{array}$ \\
\hline Cor do Plasma & Vermelho-amarelo & $\begin{array}{l}\text { Amarelo claro e } \\
\text { dominios vermelho- } \\
\text { amarelo claros }\end{array}$ & $\begin{array}{l}\text { Amarelo claro e } \\
\text { Domínios varmelho- } \\
\text { amarelo claros }\end{array}$ & $\begin{array}{l}\text { Amarelo claro e } \\
\text { amarelo brunado }\end{array}$ \\
\hline Feiçōes iluviais & Ausentes & Ausentes & Ausentes & Ausentes \\
\hline $\begin{array}{c}\text { Feiches } \\
\text { pedobiologicas }\end{array}$ & $\begin{array}{c}\text { Microagregação: } \\
\text { Canais }\end{array}$ & $\begin{array}{c}\text { Microagregaçao, raros } \\
\text { canais }\end{array}$ & $\begin{array}{c}\text { Microagregaça, raros } \\
\text { canais }\end{array}$ & raros canais \\
\hline
\end{tabular}


transição e solos hidromórficos), para estudo de características físicas, químicas, mineralógicas e micromorfológicas.

1.As partes elevadas da colina são dominadas por Latossolo Vermelho-Amarelo; a região de transição, por Latossolo Vermelho-Amarelo e Podzólico Plíntico intergradacionais, e as partes baixas por Areia Quartzosa Hidromórfica. O material de origem dos solos de toda a seqüência é heterogêneo, basicamente granítico, com presença localizada de materiais mais máficos.

2.Nas partes altas da colina o gradiente textural é menor e a argila é composta de caulinita e de óxidos de ferro predominantemente nas formas cristalinas. $\mathrm{O}$ gradiente textural aumenta encosta abaixo e as formas de ferro se tornam menos cristalinas. No fundo do vale persiste um manto profundo arenoso. Os óxidos de ferro do plasma desaparecem, restando a caulinita em pequenas proporções, evidenciando um mecanismo de destruição de plasma argiloso oxídico. Foram encontradas ainda mica nas partes inferiores dos perfis e vermiculita com hidróxi nas entrecamadas nas partes superiores.

3. Todos os solos apresentam elevada saturação por alumínio. A diferenciação lateral dos solos é devida, não a descontinuidades litológicas, mas a processos pedogenéticos de destruição e/ou remoção da fração fina, por processos de ferrólise e acidólise, evidenciados pela destruição de plasma argiloso ao nível micropedológico.

\section{REFERÊNCIAS BIBLIOGRÁFICAS}

AltemUlleR, H.J. \& KLINGE, H. Micromorphological investigation on development of podzol in Amazon basin. Plön, Max Plank Institute of Limnology. Soil Micromorphology, 1964. p. 295-305.

ANDRADE, H. Evolução de uma seqüência de solos argilosos até arenosos no complexo guianense da Amazônia Ocidental. Piracicaba, ESALQ/USP, 1990. 179 p. (tese de Doutoramento).

BARSHAD, I. Chemistry of Soil development. In: BEAR, F.E. ed. Chemistry of the Soil. New York, Reinhold, 1964.

BENITES, V.M. 1998. Caracterização Química e Espectroscópica da Matéria Orgânica e suas relações com a gênese de solos da Serra do Brigadeiro, Zona da Mata mineira. Viçosa, Imprensa Universitária. (Tese de Mestrado).

BLUME, H.P. \& SCHWERTMANN, U. Genetic evaluation of profile distribution of aluminium, iron and manganese oxides. Soil Sci. Soc. Am. Proc., Madison, 33 (3): 438-444, 1969.

BRASIL, Ministério das Minas e Energia. Projeto RADAMBRASIL. Folha NA. 20 Boa Vista e parte das Folhas NA. 21. Tumucumaque, Na. 20 Roraima e Na. 21. Rio de Janeiro, 1975.

BRASIL, Ministério das Minas e Energia. Projeto RADAMBRASIL. Folha SA.20 Manaus. Rio de Janeiro, 1978.

BRAVARD, S \& RIGHI, D. 1990. Micromorphology of na OxisolSpodosol catena in Amazonia. In: L. A. Douglas Soil Micromorphology: a basic and applied science. Developments in Soil Science 19, Elsevier, Amsterdã. 1990. pp169-174.

BREWER, R. Fabric and mineral analysis of soils. New York, Robert E. Krieger, 1976. 482 p.

BRINDLEY, G.W.; \& BROWN, G. 1980. Crystal structures of Clay minerals and their XRD identification. Mineralogical Society (ed.) London.

BRINKMAN, R. Ferrolysis, a hydromorphic soil forming process. Geoderma, Amsterdam, 3:199-206, 1970.

CAGAUN. B. e UEHARA, G. Soil anisotropy in relation to aggregate stability. Proc. Soil Sci. Soc. Am., Madison, 29:198-200, 1965. CAMPOS, J.C.F. 1998. Solos, Geomorfologia e Evolução da Paisagem do Alto e Médio Jequitinhonha, MG. Universidade Federal de Viçosa, Imprensa Universitária. Tese de mestrado.

CHAUVEL, A. Contribuição para o estudo da evolução dos Latossolos Amarelos distróficos, argilosos na borda do Platô, na região de Manaus: mecanismos de gibbsitização. Acta Amazônica, Manaus, 11:227-245, 1981.

CHAUVEL, A. Os Latossolos Amarelos distróficos, argilosos dentro dos ecossistemas das bacias experimentais do INPA e da região vizinha. Suplemento Acta Amazônica, Manaus, 12:47-60, 1982a.

CHAUVEL, A.; BOULET, R.; JOIN, P. e BOCQUIER, G. Aluminium and iron oxi-hydroxide segregation in nodules of Latossols developed on tertiary sediments (Barreiras Group) near Manaus (Amazon Basin), Brasil. In: INTERNATIONAL SEMINAR ON LATERITISATION PROCESSES, 2, São Paulo, 1982. São Paulo, Instituto Astronômico e geofísico/USP, 1982b. p. $507-526$.

COCHRANE, T. T. \& SANCHEZ, P. A. Land resources, soils and their management in the Amazonia region : a state of Knowledge report. In: S. B. HECHT (ed.) agriculture and land use reseMEKARU, T. \& UEHARA, G.arch. Cali, CIAT, 1982. p. 137-209.

DAY, T. H. Guia preliminar para classificação dos solos do vale do Baixo Amazonas. Belém, SPVEA. 1958. 38 p. (recursos Naturais, 3).

DAY, T. H. Guide to the classification of the late tertiary and quaternary soils of the lower Amazon Valley. Rome, FAO. 1959. $59 \mathrm{p}$.

EMPRESA BRASILEIRA DE PESQUISA AGROPECUÁRIA. Serviço Nacional de Levantamento e Conservação de Solos e Sociedade Brasileira de Ciência do Solo. Guia de Excursão do XVII Congresso Brasileiro de Ciência do Solo. Manaus, 1979a. $71 \mathrm{p}$.

EMPRESA BRASILEIRA DE PESQUISA AGROPECUÁRIA. Serviço Nacional de Levantamento e Conservação de Solos. Manual de método de análise de solo. Rio de Janeiro, 1979b. $235 \mathrm{p}$.

EMPRESA BRASILEIRA DE PESQUISA AGROPECUÁRIA. Serviço Nacional de Levantamento e Conservação de Solos. Mapa de solos do Brasil. Rio de Janeiro, 1981.

EMPRESA BRASILEIRA DE PESQUISA AGROPECUÁRIA. Serviço Nacional de Levantamento e Conservação de Solos. Critérios para distinção de classes de solos e de fases de unidades de mapeamento: Não mais em uso pelo SNLCS. Rio de Janeiro, 1988. 67 p. (SNLCS, 11).

FALESI, I.C. Contribuição ao estudo dos solos de Altamira (Região Fisiográfica do Xingu). Belém. Instituto de Pesquisas e Experimentação Agropecuárias do Norte, 1967. 47p. (Circular, 10).

FALESI, I.C. Os solos da Rodovia Transamazônica. Bol. Téc. IPEAN, Belém, 55:1-196. 1972.

FALESI, I.C. Os Solos de Monte Alegre. Belém. Instituto de Pesquisa e Experimentação Agropecuárias do Norte, 1970. 127p. (Série Solos da Amazônia, v.2, n.1)

FANNING, D. S. e KERAMIDAS, V. Z. Micas. In: DIXON, J. B. e WEED, S. B., eds. Minerals in soil environments. Madison, Soil Sci. of America, 1977. p. 195-258.

FITZPATRICK, E.A. 1993. Soil Microscopy and Micromorphology. John Wiley, Chichester.

GOMES, I.A. Oxisols and Inceptsols from gnesis in a subtropical area of Espírito Santo State, Brazil. West Lafayette, Purdue University, 1976. 115p. (Tese M.S.)

GUALBERTO, V.; RESENDE, M.; CURI, N. Química e mineralogia de solos com altos teores de ferro da Amaz nia e do Planalto Central. R. bras. Ci. Solo, 11:245-252, 1987.

JACKSON, M. L. Soil chemical analisys. Advanced course. Madison, Wisconsin University, 1973. 895 p.

KÄMPF, N. \& SCHWERTMANN, U. Relações entre óxidos de ferro e a cor de solos cauliníticos do Rio Grande do Sul. R. Bras. Ci. Solo, 7: 27-31, 1983.

KÄMPF, N. O ferro no solo. In: REUNIÃO SOBRE FERRO EM 

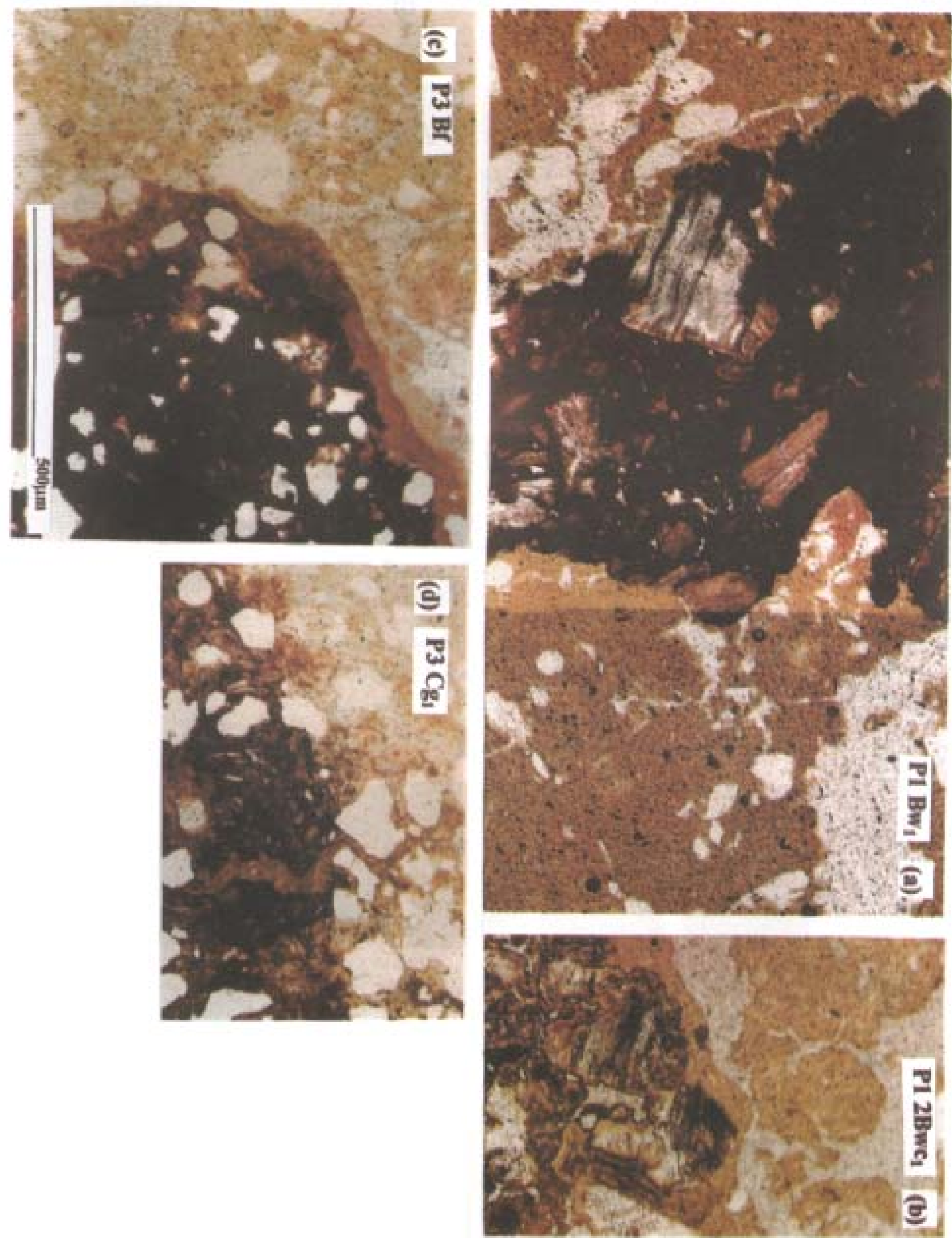

Figura 3: Fotomicrografias de seções-finas representativas dos horizontes de solos, ilustrando as variações de cor, relação plasmalesqueleto e distribuição de feições pedológicas específicas.

Figure 3: Photomicographs of thin-section of all soils, illustrating the variations on colour, skeletn/plasm distribution and pedologic features. 


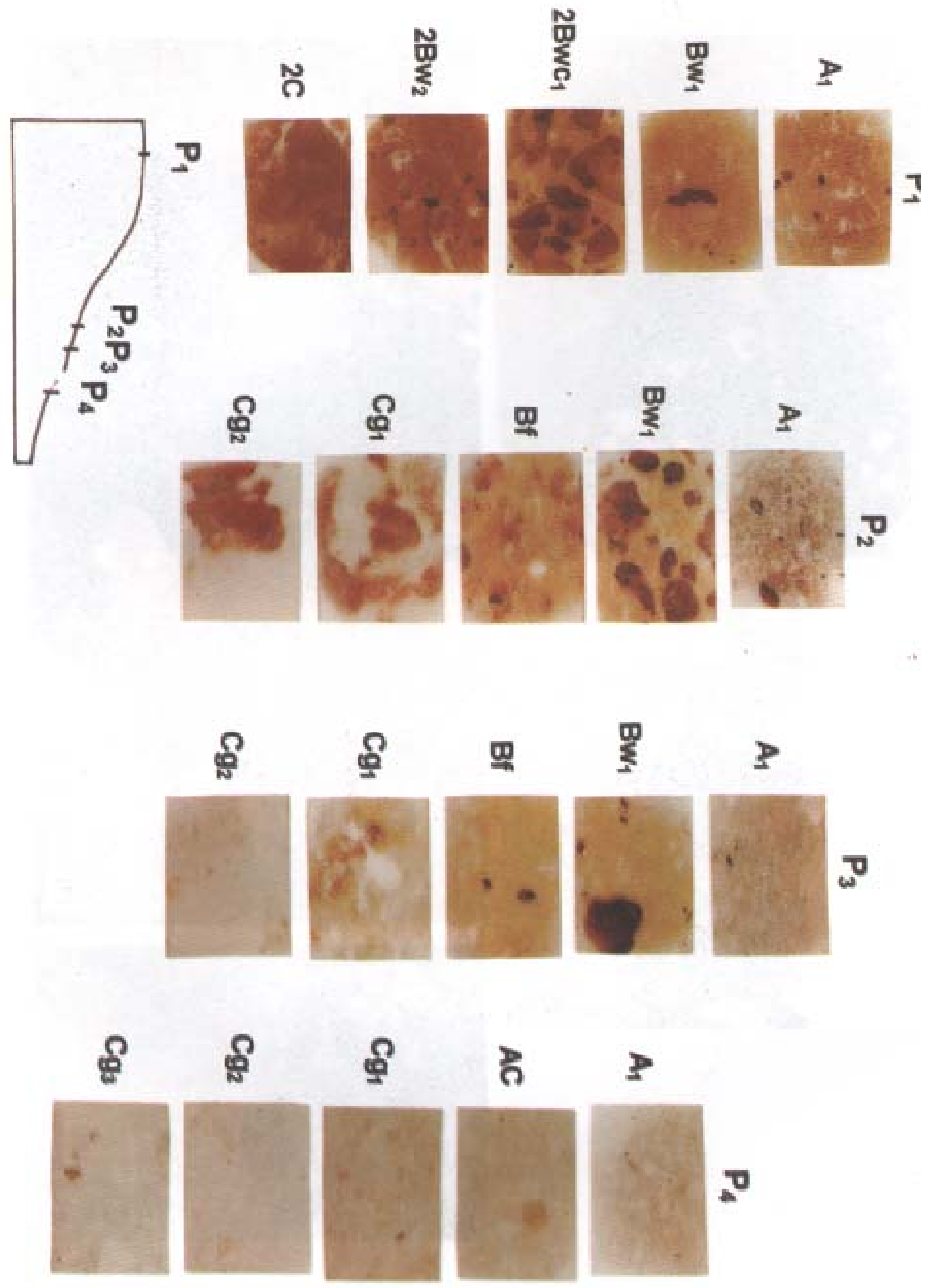

Figura 4: Feições micropedológicas destacadas em alguns horizontes de solos.

Figure 4: Micropedological features highlighted in some soils horizonts. 
SOLOS INUNDADOS, 1, Goiânia, 1988. Anais... Goiânia, EMBRAPA - CNPAF, 1988, P.35-71.

KÄMPF, N.; KLAMT, E.; SCHNEIDER, P. Óxidos de ferro em latossolos do Brasil sul e sudeste. In: Reunião de classificação, correlação de solos e interpretação de aptidão agrícola, 3, Rio de Janeiro, 1988. Anais... Rio de Janeiro, EMBRAPA - SNLCS, SBCS, 1988. p. 153-184

KITAKAWA, Y. \& MÖLLER, M. R. F. Clay mineralogy af some typical soil in the Brazilian Amazon region. Pesq. Agropec. Bras. 14(3): 201-28. 1977.

KLINGE, H. Podzol soils in the Amazon basin. Journal of Soil Science, London, 16:96-1-3, 1965.

KLINGE, H. Podzol soils: a source black- water rivers Amazonia. In SIMPÓSIO SOBRE A BIOTA AMAZÔNICA. Belém, 1966, Atas... Rio de Janeiro, Conselho Nacional de Pesquisa, 1967 v.3: Limnologia, p. 117-25.

LEPSCH, I.F. Soil-landscape relationship in na area of the Occidental Plateau of São Paulo, Brazil. Raleigh, North Carolina State University, 1975. $163 \mathrm{p}(\mathrm{PhD}$ Thesis).

LUCAS, Y.; CHAUVEL, A.; BOULET, R.; RANZANI, G. e SCATOLINI, F. Transição latossolos-podzóis sobre a Formação Barreiras na região de Manaus, Amazônia. Revista Brasileira de Ciência do Solo, Campinas, 8:325-335, 1984.

McKEAGUE, J.A., DAY, J.H. Dithionite and oxalate-extractable Fe and $\mathrm{AI}$ as aids in differentiating various classes of soils. Can. J. Soil Sci. v.46, 13-22. 1966.

MEHRA, O. P. e JACKSON, M. L. iron oxide removal from soils and clys by a dithionite-citrate system beffered with sodium bicarbonate. Clays Clay Miner., Clarkson, 7:317-327, 1960.

MEKARU, T. \& UEHARA, G. Anion adsorption in ferruginous tropical soils. Soil Sci. Soc. Am. Proc., Madison, 36(2): 296300, 1972.

MÖLLER, M. R. F. \& KITAKAWA, Y. Mineralogia de Argilas em Cambissolos do Sudoeste da Amazônia. Belém. CPATU, 1982. $19 \mathrm{p}$.

MONIZ, A.C.; BUOL, S. W. e WEED, S. B. Formation of an OxisolUltisol transition in São Paulo. II Lateral dynamics of the mical weathering. Soil Sci. Soc. Am. J., Madison, 54:1234-1239, 1982.

PÖTTER, R.O. \& KÄMPF, N. Argilo-minerais e óxidos de ferro em cambissolos e latossolos sob regime climático térmico údico no Rio Grande do Sul. R. bras. Ci. Solo, 5:153-159, 1981.

REZENDE, S.B. Geomorphology, mineralogy and genesis of four soils on gneiss in Southeastern Brazil. West Lafaiette, Purdue University, 1980. 143p. (PhD Thesis).

RIBEIRO, M.V. Mineralogia da fração grosseira de Latossolos sob cerrado do minicípio de Rio Paranaíba-MG. Lavras, ESAL, $1980.51 \mathrm{p}$.

RODRIGUES, T.E. Solos da Amazônia. In: ALVAREZ, V.H.V.; FONTES, L.E.F.; FONTES, M.P.F. eds. Os solos nos grandes domínios morfoclimáticos do Brasil e o desenvolvimento sustentado. Viçosa, SBCS/UFV, 1996. p. 16-60.

RODRIGUES, T.E.; MORIKAWA, I.K.; REIS, R.S. dos; \& FALESI, I.C. Solos do Distrito agropecuário da SUFRAMA (Rod. BR 174, Manaus-AM).IPEAOC, 1971.99p.

SCHAEFER, C. E. G. \& DALRYMPLE, J., Pedogenesis and relict properties of soils with columnar structure from Roraima, North
Amazonia. GEODERMA, 71( 1996) 1-17

SCHAEFER, C. E. R. Ecogeography and human scenario in northeast Roraima, Brazil. Ciência e Cultura Journal of the Brazilian Association for the Advancement of Science. 49(4):241-252. 1997.

SCHAEFER, C.E.G.R. 1995. Micropedologia de uma sequência Latossolo-Podzólico de Viçosa, MG: Química e Morfologia da superfície de agregados dos horizontes Bw e Bt. Anais do XXV Congresso Brasileiro de Ciência de Solo, (I) 372-374.

SCHAEFER, C.E.G.R. 1996. The microstructure of Latosols as longterm biotic contruct. Proceedings of the Latin American Congress of Soil Science, (oral session presented in Comission III, Biologia do Solo, edited in CD ROM), $21 \mathrm{pp}$.

SCHAEFER, C.E.G.R. and DALRYMPLE, J.B. 1995. Landscape evolution in Roraima, north Amazonia: Planation, Paleosols and Paleoclimates. Zeit. fur Geomorphologie, 39 (1):1-28.

SCHAEFER, C.E.R. LIMA, P.C; NASCIMENTO. 1995. Micromorfologia de Horizontes B de latossolos brasileiros. Resumos expandidos (III):1610-1613

SCHWERTMANN U. \& TAYLOR R. M. Iron oxides. In: DIXON, J. B. \& WEED, S. B., eds. Minerals in Soil Environments $2^{\mathrm{a}}$ ed. Madison, Soil Science Society of America, 1989. 379-438p.

SCHWERTMANN, U. e TAYLOR, R. M. Iron oxides. In: DIXON, J. B. e WEED, S. B., eds. Minerals in soil enviromments. madison, Soil Science Society of America, 1977. p. 145-180.

MARBUTT, C.F.. The soils of the Amazon basin in relation to Agricultural possibilities. Life and work of Curtis Fletcher Marbut. SOIL SCIENCE SOCIETY OF AMERICA, Madison, s.d. p. 119-142.

SOMBROEK, W.G. Amazon Soils: a reconnaissance of the soils of the Brazilian Amazon region. Wageningen, Center for agriculture publications and documentation, 1966. 292p.

TYLER, L.E.; RIECKEN, F.F. \& ALLEN, J.S. Properties and genesis of soils developed in very firm till in northeastern Iowa. Soil Sci. Soc. Am. Proc., Madison, 26:275-81, 1962.

UEHARA, G; FLACH, W. e SHERMAN, G. D. Genesis and micromorphology of certain strutural soil types in Hawaiian Latosols and their significance to agriculture pratices. In: TRANS. COMM. IV AND V INT. SOC. SOIL SCI., New Zealand, 1962. p. 264-270.

UNIVERSIDADE FEDERAL DE VIÇOSA. Levantamento exploratório com intensidade, de solos do Centro-Oeste do Estado do Pará. Viçosa, Convênio INCRA-UFV, 1979. 266p.

VAN WAMBEKE, A .R. Criteria for classifying tropical soils by age. J. Soil Sci., Edinburgh, 13: 124-132. 1962.

Van BREEMEN, N. Long-term chemical, mineralogical and morphological effects on Fe-redox processes in periodically flooded soils. In: Stucki, J.W.; GOODMAN, B. \& SCHWERTMANN, U. ed. Iron in soils and clay minerals. NATO Advanced Studies Institute, Bad Windsheim, 1985. Pp 811-820.

VETTORI, L. Métodos de análise de solo. Equipe de pedologia e fertilidade de solos. rio de Janeiro. Ministério da Agricultura, 1969. 24 p. (Boletim técnico, 7)

VIEIRA, L.S. Os solos do Estado do Pará. Belém, IDESP, 1971. 175p. (Cadernos Paraenses, 8). 